\title{
CORRECTIONS
}

\section{Publisher Correction: Non-invasive molecular imaging of kidney diseases}

Barbara M. Klinkhammer (D), Twan Lammers (D), Felix M. Mottaghy (D), Fabian Kiessling (D), Jürgen Floege and Peter Boor (D)

Correction to: Nature Reviews Nephrology https://doi.org/10.1038/s41581-021-00440-4, published online 29 June 2021.

The original version of this article misspelled the name of L.J. Zhang in the 'Peer review information' section, as L.J. Zhiang. This error has now been corrected in the HTML and PDF versions of the article.

https://doi.org/10.1038/s41581-021-00464-w I Published online 5 July 2021

(c) Springer Nature Limited 2021

\section{Publisher Correction: Sustainable Development Goals relevant to kidney health: an update on progress}

Valerie A. Luyckx@, Ziyad Al-Aly(1), Aminu K. Bello, Ezequiel Bellorin-Font, Raul G. Carlini, June Fabian(1), Guillermo Garcia-Garcia (), Arpana lyengar, Mohammed Sekkarie, Wim van Biesen (1), Ifeoma Ulasi, Karen Yeates and John Stanifer

Correction to: Nature Reviews Nephrology https://doi.org/10.1038/s41581-020-00363-6, published online 13 November 2020.

In Figure 2 of this Review, the Urinalysis (quantitative) data points were incorrectly labelled as Dialysis (quantitative). This error has been corrected in the HTML and PDF versions of the manuscript.

https://doi.org/10.1038/s41581-021-00473-9 I Published online 2 August 2021

(c) Springer Nature Limited 2021 